\title{
Factors Influencing the Efficacy of Myclobutanil and Azoxystrobin for Control of Grape Black Rot
}

\author{
Lisa Emele Hoffman and Wayne F. Wilcox, Department of Plant Pathology, Cornell University, New York State \\ Agricultural Experiment Station, Geneva 14456
}

\begin{abstract}
Hoffman, L. E., and Wilcox, W. F. 2003. Factors influencing the efficacy of myclobutanil and azoxystrobin for control of grape black rot. 87:273-281.

We studied several factors influencing the efficacy of the demethylation inhibitor (DMI) fungicide myclobutanil and the strobilurin fungicide azoxystrobin for control of grape black rot, caused by the pathogen Guignardia bidwellii (anamorph Phyllosticta ampelicida). The distribution of sensitivities to myclobutanil among G. bidwellii isolates from an "organic" vineyard (no previous exposure to synthetic fungicides, $\mathrm{n}=50$ ) and from a commercial vineyard with a history of DMI applications $(n=60)$ was determined in vitro. There was little difference between the two populations, and the range of sensitivities was narrow; for the composite population of 110 isolates, the value of the mean effective dose for $50 \%$ inhibition $\left(\mathrm{ED}_{50}\right)$ was $0.04 \mathrm{mg} / \mathrm{liter}$, and the most- and least-sensitive isolates were separated by a factor of 16 . When applied from 2 to 6 days after inoculating grape seedlings with a suspension containing either $2 \times 10^{4}$ or $1 \times 10^{6}$ conidia per ml, myclobutanil $(60 \mathrm{mg} / \mathrm{liter})$ provided complete control of lesion development. When applied beyond 6 days after inoculation but prior to lesion appearance ( 9 to 11 days after inoculation, depending on temperature), it provided complete control of pycnidium production in those lesions that developed subsequently. In contrast, when applied 2 to 10 days after inoculation with $2 \times 10^{4}$ conidia per ml, azoxystrobin ( $128 \mathrm{mg} /$ liter) provided only 78 to $63 \%$ control of lesion formation and erratic control of pycnidium formation, although conidium production was reduced by 85 to $68 \%$ across this range of treatments. Relatively little control was provided by azoxystrobin treatments following inoculation with $1 \times 10^{6}$ conidia per ml. On leaf disks treated with azoxystrobin at $20 \mathrm{mg} /$ liter prior to inoculation, 8 to $43 \%$ of conidia from five $G$. bidwellii isolates germinated, and 4 to $19 \%$ formed appressoria. However, these processes were completely to near-completely inhibited when salicylhydroxamic acid (SHAM), which inhibits an alternative respiration pathway utilized to circumvent the activity of strobilurin fungicides, was added to the inoculum at $100 \mathrm{mg} /$ liter. Thus, alternative respiration apparently allowed the conidia to germinate and form appressoria on azoxystrobin-treated leaves. When grape seedlings were sprayed with commercially formulated azoxystrobin at $200 \mathrm{mg} / \mathrm{liter}$ and inoculated the next day with $G$. bidwellii conidia, little or no disease was evident 4 weeks later. However, G. bidwellii pycnidia formed on up to $50 \%$ of the leaves from such plants when they were killed with paraquat 1 to 7 days after inoculation. These results suggest that latent infections became established on azoxystrobin-treated leaves and became active after the plants were killed with paraquat.
\end{abstract}

Black rot of grape, caused by the fungus Guignardia bidwellii (Ellis) Viala \& Ravaz (anamorph: Phyllosticta ampelicida (Englem.) Van Der Aa), can cause substantial losses of grapes in climates with humid summers (11). Fruit infections leading to yield loss and build-up of overwintering inoculum are managed primarily with fungicide applications, although sanitation and canopy management can effectively augment such sprays (10). Fruit of Vitis $\times$

Corresponding author: L. E. Hoffman

E-mail: lisa-emele.hoffman@usa.dupont.com

Current address of first author: E.I. DuPont de Nemours \& Co., Stine-Haskell Research Center, Newark, DE 19714.

Accepted for publication 9 October 2002.

Publication no. D-2002-1230-01R

(C) 2003 The American Phytopathological Society labruscana 'Concord', the most widely planted native American variety, are susceptible from bloom until 4 to 5 weeks later $(7,10,12)$, whereas fruit of Vitis vinifera 'Chardonnay' and 'Riesling' retain some susceptibility for another 1 to 2 weeks $(10,12)$. When used in conjunction with good sanitation, i.e., removing mummies from the trellis and dropping them to the ground during annual dormant pruning, three applications of the sterol demethylation inhibitor (DMI) fungicide myclobutanil immediately prior to bloom, plus 2 and 4 weeks later, provided virtually complete control of fruit rot over five consecutive years of testing (10). Whereas some DMI fungicides, e.g., myclobutanil and tebuconazole, provide excellent control of black rot and also are effective against powdery mildew, caused by Uncinula necator, certain strobilurin fungicides have an advantage in integrated management programs, because they are also active against Plasmopara viticola, the causal agent of grapevine downy mildew. Furthermore, the strobilurins are recommended as rotational partners with the DMIs to improve control and thereby reduce the selection of pathogen isolates resistant to these fungicides $(28,29)$. Although DMI resistance in $U$. necator has been well documented $(6,30,31)$, resistance to the DMIs by $G$. bidwellii has received little study (22).

In order to make informed decisions about the fungicidal component of integrated management programs, the physical modes of action $(13,20)$ of these materials against different diseases need to be understood. DMI fungicides are systemic, and because some are labeled for control of black rot when applied up to 3 days postinfection, they have been incorporated into curative spray programs $(5,8)$. However, our field studies (10) and preliminary greenhouse experiments (11) suggested that the extent of the postinfection activity provided by myclobutanil, including antisporulant effects, may be more extensive than previously thought. In comparison, approximately 1 to $3 \%$ of applied azoxystrobin was absorbed into the leaves of grapevines within $24 \mathrm{~h}$ of application (2), suggesting azoxystrobin may exhibit limited postinfection activity against $G$. bidwellii. However, azoxystrobin demonstrated both translaminar movement (27) and some postinfection activity against downy mildew (27) and powdery mildew (28) in grapes. Additionally, uptake of the strobilurin fungicides by plant cells is quite variable among different class members. Whereas several strobilurin fungicides have provided good control of black rot in field trials (23-25), little is known about their physical modes of action against this disease.

Because some fungal isolates are able to grow in the presence of the strobilurins via alternative respiration (16-18,29,32), the potential for compromised control exists. Using this pathway, fungi are able to circumvent the strobilurin target site in the mitochondrial $\mathrm{bc}_{1}$ complex and reduce $\mathrm{O}_{2}$, even in the presence of the fungicide, albeit at a much reduced rate $(1,16,29)$. Conidia of Venturia inaequalis were able to germinate via this pathway in the presence of kresoxim-methyl on polystyrene surfaces, but extensive germination studies were not performed in planta $(17,18)$. However, it is still unknown whether suffi- 
cient respiration may occur to allow quiescent survival until inhibitory levels of the fungicide have dissipated. The G. bidwellii-grapevine system provides an excellent opportunity to study this phenomenon since G. bidwellii can survive latently in grape leaves for extended periods, then grow saprophytically after the tissue is killed with paraquat (15).

Therefore, the primary objectives of this study were to (i) determine the distribution of sensitivities to myclobutanil within both a baseline population of G. bidwellii and one with the potential for containing an elevated level of resistant individuals; (ii) compare and contrast the postinfection activity of myclobutanil and the strobilurin fungicide azoxystrobin against $G$. bidwellii; and (iii) determine if G. bidwellii conidia can utilize alternative respiration to germinate, infect, and survive latently in planta in the presence of azoxystrobin. A brief portion of this study has been published previously (11).

\section{MATERIALS AND METHODS}

Myclobutanil sensitivity distributions. In 1999 and 2000, leaves and berries expressing black rot symptoms were collected from (i) an "organic" vineyard (no previous exposure to synthetic fungicides) of Vitis $\times$ labruscana 'Concord' in Burdette, NY $(6,28)$, which represented a baseline population of G. bidwellii, and (ii) a vineyard of $V . \times$ labruscana 'Delaware', located in Naples, NY, in which control of black rot with myclobutanil has been problematic (10). Both vineyards were over 1 ha in size, and symptomatic leaves and berries were collected at random from vines at least $10 \mathrm{~m}$ apart to reduce the probability of collecting clonal isolates.

Symptomatic leaves and berries were surface-sterilized in 10\% household bleach and cultured on half-strength potato dextrose agar (PDA) (Difco Laboratories, Detroit, MI). Because G. bidwellii conidia germinate poorly, if at all, on agar media (14), single-sporing was not possible. Instead, isolates were grown on water agar (16 $\mathrm{g}$ of agar per liter) for approximately $48 \mathrm{~h}$ and then hyphal-tipped with the aid of a dissecting microscope. Fifty isolates from the baseline population and 60 isolates from the fungicide-exposed population were collected over 2 years. Isolates were stored on water agar slants at room temperature under fluorescent light and transferred every 3 to 4 months. To reduce the potential for sensitivity shifts in culture, fungicide sensitivity determinations were conducted within 6 months of acquiring each isolate, and as few transfers as possible were made during that time.

For fungicide sensitivity determinations, three mycelial plugs approximately $6 \mathrm{~mm}$ in diameter per isolate were cut with a no. 3 cork borer and placed on 5\% malt extract agar (MEA) amended with myclobutanil. Stock solutions were prepared by dissolv- ing technical grade myclobutanil (Dow AgroSciences, Indianapolis, IN) in acetone, with subsequent twofold dilutions in additional acetone. These were stored at $-20^{\circ} \mathrm{C}$ until just before plates were poured, when a $0.5-\mathrm{ml}$ aliquot was added to $500 \mathrm{ml}$ of warm $\left(55^{\circ} \mathrm{C}\right) 5 \%$ MEA to produce 10 final myclobutanil concentrations ranging from 0.002 to $1.0 \mathrm{mg} / \mathrm{liter}$. A $0.1 \%$ acetone-amended and a nonamended check were included for all sensitivity determinations. Petri plates were incubated at $25^{\circ} \mathrm{C}$ for approximately 10 days before colony diameter was measured. For each isolate, the percentage of the mean colony diameter (minus the original plug) relative to the check was regressed against the log of the fungicide concentration through the linear portion of the sigmoidal dose-response curve, and the effective dose whereby $50 \%$ of the mean colony diameter was inhibited $\left(\mathrm{ED}_{50}\right)$ was calculated. Assay reproducibility was determined by assaying five isolates five times and calculating the coefficient of variation and the $95 \%$ confidence interval about the mean log-transformed $\mathrm{ED}_{50}$ value for each isolate (28). All regression analyses were performed in $\mathrm{Mi}$ crosoft Excel (Microsoft Corp. Inc., Seattle, WA). The mean $\mathrm{ED}_{50}$ value of each population was compared in a paired $t$ test.

Postinfection activities of myclobutanil and azoxystrobin. For all experiments, open-pollinated $V$. vinifera 'Riesling' seeds were stratified and planted in a pasteurized potting medium consisting of peat and sand (3:1 ratio). Seedlings were transplanted into 10 -cm-diameter pots and grown in a pathogen-free, walk-in growth chamber (Percival Scientific, Perry, IA) at $20^{\circ} \mathrm{C}, 80 \%$ relative humidity, and $12 \mathrm{~h}$ of light per day.

For inoculum production, isolate Ott0046, with moderate sensitivity to myclobutanil $\left(\mathrm{ED}_{50}=0.09 \mu \mathrm{g} / \mathrm{ml}\right)$, was grown on half-strength PDA for approximately 14 days under fluorescent light to induce sporulation. Conidia were liberated from the pycnidia by flooding the petri plates with $10 \mathrm{ml}$ of sterile distilled water (SDW) and incubating the plates on the bench top for $20 \mathrm{~min}$. Then, the plates were decanted and inoculum was mixed thoroughly for 20 min on a mixing-plate before being adjusted to the final concentration with the aid of a hemacytometer.

The postinfection activities of myclobutanil and azoxystrobin were determined initially by inoculating seedlings with three to four fully expanded leaves until runoff with a suspension containing $2 \times 10^{4}$ conidia per $\mathrm{ml}$ using a hand-held Preval sprayer (Precision Valve Corporation, Yonkers, NY). Seedlings were placed in a mist chamber for $24 \mathrm{~h}$ at $22^{\circ} \mathrm{C}$ to promote infection, then moved to a greenhouse until evaluation. Commercially formulated myclobutanil (60 mg/liter), azoxystrobin (128 $\mathrm{mg} / \mathrm{liter}$ ), or water was applied to the upper surface of the leaves until runoff either 2 ,
$4,6,8$, or 10 days later, using a modified paint sprayer operating at $207 \mathrm{kPa}$ in a small-plant spray cabinet. The sprayer was rinsed with $50 \mathrm{ml}$ of acetone and then 50 $\mathrm{ml}$ of water before spraying each treatment. For each set of experiments, eight replicate seedlings per treatment were randomly arranged in the greenhouse, and the experiment was repeated. The oldest still-expanding leaf (leaf position 1) of each seedling, marked at the time of inoculation, and the leaf immediately above that (leaf position 2) were assessed 25 days after inoculation for the number of lesions per leaf, area infected per leaf, pycnidial density per lesion area, and the number of spores recovered per pycnidium. Individual lesion areas were estimated by comparing the lesions to template squares measuring 1 to $10 \mathrm{~mm}^{2}$ in size. The number of pycnidia per lesion was counted using a dissecting microscope. The lesions containing pycnidia on each plant were excised and placed in $1 \mathrm{ml}$ of sterile distilled water for $2 \mathrm{~h}$, and then the number of conidia recovered were counted with the aid of a hemacytometer. Each measured response was averaged over the two leaves assessed per plant and then over the eight replicate seedlings per treatment. For each variable, the percentage of disease control relative to the check was then calculated and regressed against the time elapsed between inoculation and treatment, and the slope of the resultant regression line was compared to 0. Additionally, for each application date, the degree of control provided by the two compounds was compared using a two-way $t$ test. When specific data were obtained for only one compound, the control provided at each application time was similarly compared against a potential $100 \%$ control in a $t$ test. All statistical analyses were performed in Minitab v.12.0 (Minitab Inc., State College, PA).

To further determine the limits of the postinfection activity of myclobutanil, Riesling seedlings were inoculated with a suspension containing $2 \times 10^{4}$ conidia per $\mathrm{ml}$ and then treated with myclobutanil or water either $9,11,13$, or 15 days later. The black rot lesions apparent immediately prior to each fungicide application were identified with a permanent ink marker. Lesions with and without pycnidia were marked with different colors. The plants were assessed as described above, and the measured responses were averaged over the eight replicate seedlings per treatment at each leaf position. The percentage of disease control (relative to the water check) provided by myclobutanil at each application time was regressed against the time elapsed between inoculation and treatment, and the slopes of the resultant regression lines were compared to 0 . Additionally, the percentage of control provided by myclobutanil at each application time was also compared against $100 \%$ control in $t$ tests. The experiment was conducted twice. 
To determine the effect of inoculum concentration on the postinfection activities of both compounds, seedlings were inoculated with either $2 \times 10^{4}$ or $1 \times 10^{6}$ conidia per $\mathrm{ml}$, and plants were treated with azoxystrobin or myclobutanil either 4, 6,8 , or 10 days later. Eight replicate seedlings were included per treatment, and water-inoculated checks were included for each application timing. Each fungicide was assayed twice. Due to coalescence of individual lesions when plants were inoculated with the higher dose, only the percentage of symptomatic leaf area was rated; otherwise, data were gathered 25 days after inoculation, as described above. For each inoculum dose, the percentage of disease control (relative to the water check) provided by each compound was regressed against the time elapsed between inoculation and treatment, and the slopes of the resultant regression lines were compared to 0. Additionally, the percentages of disease control provided by both compounds at each inoculum concentration and application time were compared in twosample $t$ tests.

Germination and appressorium formation of $G$. bidwellii on azoxystrobintreated leaf disks. Disks were cut from the oldest still-expanding leaf of 'Riesling' seedlings using a no. 2 cork borer, randomized, and soaked for $1 \mathrm{~h}$ with repeated agitation in either water or aqueous solutions of azoxystrobin. These were prepared by dissolving technical grade fungicide in acetone to obtain an original stock solution, which was stored at $-20^{\circ} \mathrm{C}$ until immediately prior to use, then adding it to SDW at a rate of $0.2 \%$ to provide an azoxystrobin concentration of $20 \mathrm{mg} / \mathrm{liter}$. Subsequent twofold serial dilutions were made with additional SDW down to an azoxystrobin concentration of $0.2 \mathrm{mg} / \mathrm{liter}$ for a total of eight concentrations. The acetone concentration was not standardized in each dilution, but a $0.2 \%$ acetone check (the highest concentration used) was included in all assays in addition to a water check. After soaking, disks were allowed to air dry on paper towels and then placed on water agar to maintain hydration.

To prepare inoculum, conidia from five different $G$. bidwellii isolates were grown and harvested separately as previously described, then were washed to remove germination inhibitors according to the protocol of Kuo and Hoch (14). In brief, the spores were decanted into 1-ml Eppendorf tubes and vortexed for $15 \mathrm{~s}$ before being centrifuged for $10 \mathrm{~min}$ at $10,000 \times \mathrm{g}$. The supernatant was poured off and $1.5 \mathrm{ml}$ of SDW was added to each tube. The tubes were vortexed to resuspend the pellet, centrifuged for $5 \mathrm{~min}$ at $6,000 \times g$, and the supernatant again was poured off. This was repeated twice more with centrifugation for $4 \mathrm{~min}$ at $4,000 \times g$. Because $G$. bidwellii conidia attach and germinate readily only on hydrophobic surfaces such as plastic
(14), the suspension was transferred to a glass tube before adjusting to the final concentration of $3 \times 10^{5}$ conidia per $\mathrm{ml}$ with the aid of a hemacytometer. To maintain a humid environment, the insides of the petri plate lids were misted with water using a Preval sprayer before disks were inoculated with $10-\mu 1$ droplets of the individual spore suspensions. Each isolate was assayed twice.

After incubation on the bench top for 24 h, a $10-\mu 1$ droplet of $0.3 \%$ Calcofluor white (Sigma Chemical Co., St. Louis, MO) was added to each inoculum droplet, and the disks were rinsed in SDW 10 s later. Then, the disks were dried on filter paper and mounted in glycerol. Using ultraviolet illumination at $\times 300$ magnification, 100 spores were assessed for germination and the formation of mature appressoria on each of six replicate leaf disks per treatment. Spores were considered germinated if the germ tube was at least the length of the conidium or had formed at least an immature appressorium. Mature appressoria appeared dark blue under UV light, and were clearly visible with a brown appearance under white light.

To determine if conidia could germinate and form appressoria in the presence of azoxystrobin via alternative respiration, leaf disks treated with a single high dose of azoxystrobin ( $20 \mathrm{mg} / \mathrm{liter})$ also were inoculated with separate spore suspensions of the same five $G$. bidwellii isolates amended with $100 \mathrm{mg}$ of salicylhydroxamic acid per liter (SHAM, Sigma), which inhibits alternative respiration $(1,17,18)$. Because SHAM will not dissolve in pure acetone, and because high concentrations of methanol affected both germination and appressorium formation in preliminary experiments, a $1 \mathrm{~g} /$ liter SHAM stock solution was prepared in a mix of 1 volume methanol: 2 volumes acetone. After harvesting conidia, an appropriate aliquot of SHAM stock solution and/or SDW was added to the inoculum suspensions to provide a final inoculum concentration of $3 \times$ $10^{5}$ conidia per $\mathrm{ml}$ and $100 \mathrm{mg} / \mathrm{liter}$ SHAM, then leaf disks previously soaked in azoxystrobin or SDW were inoculated and treated as above. Check treatments included droplets amended with the SHAM solution or the methanol-acetone components only, inoculated onto disks soaked in SDW. Leaf disks were allowed to incubate for approximately $24 \mathrm{~h}$ before six disks per treatment were stained and assessed. Each isolate was assayed twice, and the treatment means for the combined data from both assays were subjected to analysis of variance and separated using the WallerDuncan $k$-ratio $t$ test $(k=100)$. All statistical analyses were performed in SAS (SAS Institute, Cary, NC).

Ability of G. bidwellii to infect and survive latently on azoxystrobin-treated leaves. The typical concentrations of azoxystrobin applied in vineyards, about 100 to
$200 \mathrm{mg} / \mathrm{liter}$, far exceeded the water solubility of the technical grade compound. Thus, to mimic field conditions, additional experiments were performed using a commercially formulated product, Abound 80WG. (This formulation was chosen over the standard commercial flowable formulation in order to facilitate dispensing small quantities). To determine the ability of $G$. bidwellii to utilize alternative respiration for germination and appressorium formation on leaves treated with field rates of azoxystrobin, the oldest still-expanding leaf was detached from seedlings and the upper surface was sprayed until runoff with (i) $200 \mathrm{mg}$ azoxystrobin per liter; (ii) 20 mg azoxystrobin per liter, for comparison with previous experiments; or (iii) water alone, using a modified paint sprayer operating at a pressure of $207 \mathrm{kPa}$. Leaves were allowed to dry thoroughly, then disks were excised, placed on water agar, and inoculated with a $10-\mu 1$ droplet of a suspension containing $3 \times 10^{5}$ conidia of isolate Ott0030 per milliliter, with or without the SHAM amendment. Six disks per treatment were assessed for percent germination and appressorium formation after incubation for $24 \mathrm{~h}$, as described above. The treatment means were averaged over two runs of the experiment and then subjected to analysis of variance and separated using the Waller-Duncan $k$-ratio $t$ test $(k=100)$.

To determine the ability of G. bidwellii to survive latently in leaves treated with these rates of azoxystrobin, intact seedlings with four to five leaves were sprayed as above and inoculated 24 h later with $3 \times$ $10^{5}$ conidia per $\mathrm{ml}$ (or, in a secondary experiment, with $1 \times 10^{6}$ conidia per $\mathrm{ml}$ ) of isolate Ott0030. To more closely simulate field conditions, spores were not washed prior to inoculation. Either 1, 3, or 7 days after inoculation, selected plants were treated with a $0.1 \%$ concentration of commercially formulated paraquat (Gramoxone, Syngenta Crop Protection, Greensboro, NC) and allowed to dry overnight in a fume hood. Noninoculated plants and inoculated plants not previously sprayed with fungicide also were treated with paraquat 3 days after inoculation, to serve as controls. The youngest three leaves of all plants treated with paraquat were excised the next day, placed in petri plates containing moistened filter paper, and incubated in the greenhouse for approximately 4 weeks before assessing them for the presence of $G$. bidwellii pycnidia. Pycnidia were confirmed as those of $G$. bidwellii based on their erumpent nature and the size and morphology of the conidia (19) examined subsequently in squash mounts. Seedlings not treated with paraquat were left intact in the greenhouse, and the youngest three leaves present at the time of inoculation were assessed for the presence of black rot lesions at the same time as the paraquat-treated leaves. The percentage of infected leaves was calcu- 
lated for each seedling and averaged over the 10 replicate seedlings per treatment. The experiment was conducted twice, and the means from each run of the experiment were subjected to analysis of variance and separated using the Waller-Duncan $k$-ratio $t$ test $(k=100)$.

\section{RESULTS}

Distribution of $G$. bidwellii sensitivities to myclobutanil. The coefficient of variation based upon the $\log -\mathrm{ED}_{50}$ values determined for five isolates repeated five times ranged from 2 to $4 \%$. The mean coefficient of variation was $3 \%$, and the $95 \%$

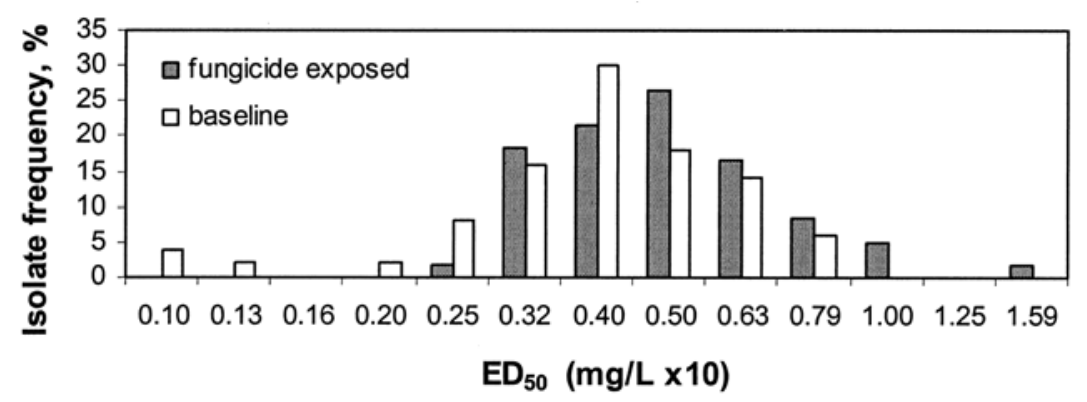

Fig. 1. Distribution of sensitivities to myclobutanil among 50 Guignardia bidwellii isolates from a baseline population collected in Burdette, NY, and among 60 isolates from a population routinely exposed to demethylation inhibitor (DMI) fungicides collected in Naples, NY. The effective doses for 50\% inhibition of mycelial growth $\left(\mathrm{ED}_{50}\right.$ values) were determined by regressing the percentage of colony diameter (relative to the control) obtained on myclobutanil-amended malt extract agar against the $\log$ of the fungicide concentration. Each isolate was assayed three times, and the mean values are reported.
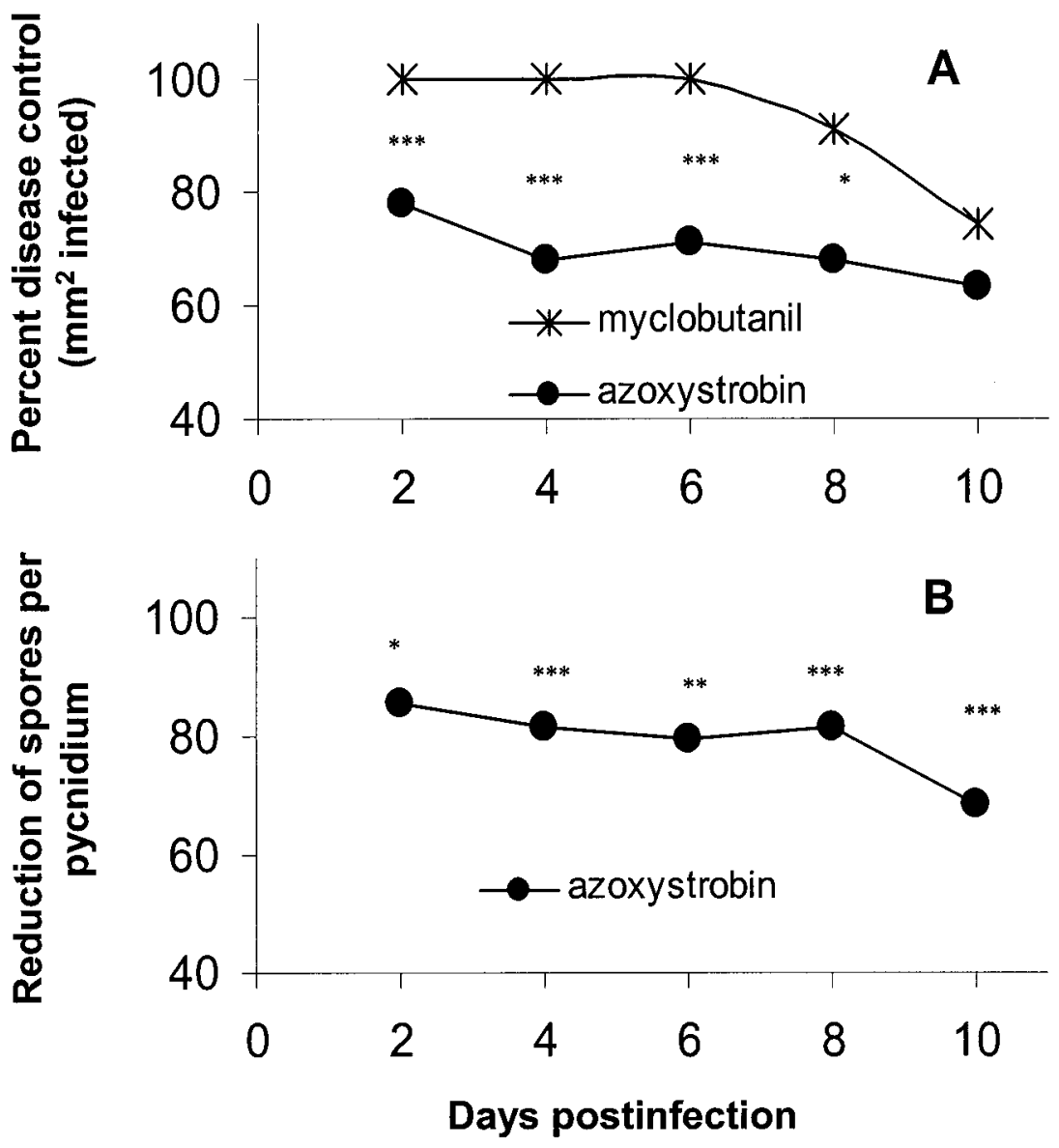

Fig. 2. Postinfection activities of myclobutanil $(60 \mathrm{mg} / \mathrm{liter})$ and azoxystrobin $(128 \mathrm{mg} / \mathrm{liter})$ applied either 2, 4, 6, 8, or 10 days after inoculation with $2 \times 10^{4}$ conidia of Guignardia bidwellii per $\mathrm{ml}$. Values are means of two leaves each on eight replicate seedlings per treatment within each of two experiments. A, Percent control of disease severity. Significant differences between the two fungicides at individual application times are indicated by $*(P \leq 0.1)$;** $(P \leq 0.05)$; and *** $(P \leq 0.01)$. B, Antisporulant effects. Significant deviations from $100 \%$ control are indicated by $*(P \leq 0.1) ; * *(P$ $\leq 0.05)$; and $* * *(P \leq 0.01)$. No pycnidia developed in leaves treated with myclobutanil up to 8 days postinfection and few developed in the 10 day postinoculation treatment.

confidence interval ranged from 14 to $32 \%$ with respect to the mean $\mathrm{ED}_{50}$ values, indicating that this assay for determining the sensitivity of $G$. bidwellii to myclobutanil was highly reproducible. The $\mathrm{ED}_{50}$ values for the baseline population were narrowly distributed, ranging only from 0.01 to 0.08 $\mathrm{mg} /$ liter $($ mean $=0.04 \mathrm{mg} / \mathrm{liter}$ ), while the $\mathrm{ED}_{50}$ values within the exposed population were generally comparable, ranging from 0.025 to $0.16 \mathrm{mg} / \mathrm{liter}$ (mean $=0.05$ $\mathrm{mg} / \mathrm{liter}$ ) (Fig. 1). Thus, the lowest and highest $\mathrm{ED}_{50}$ values within this composite sample of 110 isolates were separated only by a factor of 16 . The means of the two populations were not significantly different when compared in a paired $t$ test $(P \leq 0.6)$

Comparative postinfection activities of myclobutanil and azoxystrobin. Myclobutanil applied from 2 to 6 days after inoculation (i.e., 9 to 5 days prior to appearance of first symptoms) provided complete control of black rot on seedling foliage, whereas control of mean lesion area declined to 91 and $75 \%$ (relative to the check) following 8- and 10-day postinoculation treatments, respectively (Fig. 2A). No pycnidia were found in the few lesions that did form in the 8-day postinoculation treatment; similarly, pycnidium formation in lesions that developed after the 10-day postinoculation treatment was reduced by $98 \%$ relative to the check treatment, and mean spore recovery from each of these pycnidia was reduced by $64 \%$ relative to the untreated check (data not shown).

In comparison to myclobutanil, azoxystrobin applied 2 to 8 days after inoculation provided significantly less control of the area infected per plant $(P \leq 0.001$ to 0.08 ), but statistically equivalent control when applied 10 days after inoculation (Fig. 2A). The negative slope of the regression line, which was significantly different from $0(P \leq 0.06)$, indicated a linear and time-dependent reduction in control from $78 \%$ when azoxystrobin was applied on day 2 to $63 \%$ when applied on day 10 . Control of pycnidium formation ranged from 0 to $75 \%$, although this effect was erratic and inconsistent among application times and experiments (data not shown). Azoxystrobin, however, did provide consistent reduction of conidium formation within those pycnidia that developed. The degree of reduction decreased over time, from $85 \%$ when applied 2 days after inoculation to $68 \%$ when applied 10 days later (Fig. 2B).

Increasing the inoculum concentration did not affect the extent of postinfection activity for myclobutanil, but did cause a significant reduction in the amount of control provided by azoxystrobin at each application time tested. The postinfection activity of myclobutanil was similar to that observed in previous experiments, except when applied 10 days after inoculation, where control dropped from $74 \%$ in previ- 
ous experiments to $35 \%$ (Figs. 2 and 3 ). As before, when plants were inoculated with 2 $\times 10^{4}$ conidia per $\mathrm{ml}$, azoxystrobin provided curative activity that decreased significantly over time $(P \leq 0.007)$, from a high of $93 \%$ control when applied 4 days after inoculation to $61 \%$ when applied 6 days later. However, only 18 to $34 \%$ control was provided by the same treatments when plants were inoculated with $1 \times 10^{6}$ conidia per $\mathrm{ml}$, and no time-dependent response was observed (i.e., the slope of the regression line was not significantly different from $0, P \leq 0.05$ ) (Fig. 3).

Myclobutanil applied beyond 10 days after inoculation provided $<50 \%$ control of disease severity (Fig. 4), but provided excellent control of pycnidium formation when it was applied prior to lesion appearance. In fact, virtually all of the lesions containing pycnidia during the final assessment for each treatment were already evident before the associated fungicide spray (Table 1). For instance, very few lesions were apparent prior to the applications of myclobutanil 9 or 11 days after inoculation (Table 1), and no pycnidia formed in these leaves within 25 days after inoculation, even though considerable numbers of additional lesions appeared subsequent to the applications (Table 1, Fig. 4). Similarly, few lesions were evident on the older of the two leaves prior to the application 13 days after inoculation, and the number of pycnidia-bearing lesions remained comparably low when evaluated 12 days later, even though the total number of lesions had increased ninefold during this time (Table 1). The pycnidial density within all lesions on these leaves was reduced by $96 \%$ relative to the check (Fig. 4). Lesions developed more rapidly on younger leaves, i.e., $80 \%$ of the final number already were apparent when these were sprayed 13 days after inoculation (Table 1), and the reduction in the number of pycnidia-bearing lesions and pycnidial density in all lesions was only 66 and $46 \%$, respectively, at the time of evaluation (Table 1). Leaves at both positions had numerous lesions prior to the application 15 days after inoculation, and the control of pycnidium formation was similarly reduced to only 10 to $30 \%$ (Table 1, Fig. 4). Application of myclobutanil 13 and 15 days after inoculation provided 65 and $80 \%$ control of conidium formation in the pycnidia that did form in the older leaves, respectively, but provided no control of conidium formation in the pycnidia that developed in younger leaves (data not shown).

Germination and appressorium formation of $G$. bidwellii conidia on azoxystrobin-treated leaves. Complete inhibition of germination or appressorium formation was not observed for any of the five isolates inoculated onto leaves treated with azoxystrobin concentrations ranging from 0.08 to $20 \mathrm{mg} / \mathrm{liter}$ (Fig. 5). In gen- eral, the responses were linear with respect to the $\log$ of the azoxystrobin concentration, although the threshold concentration above which this occurred differed among isolates. For instance, isolates Ott0046 and Ott0030 showed no response in either germination or appressorium formation at azoxystrobin concentrations $\leq 1.25 \mathrm{mg} / \mathrm{liter}$, whereas reductions in the percentage of germination and appressorium formation for isolate Ott0034 began at a concentration of $0.6 \mathrm{mg} / \mathrm{liter}$ and isolates Ott0049 and Ott0040 responded over the entire range of concentrations tested (Fig. 5).

In subsequent tests with these same five isolates, conidium germination on leaf disks soaked in azoxystrobin at $20 \mathrm{mg} / \mathrm{liter}$ was inhibited by 43 to $85 \%$ relative to the water check, but was inhibited by $>99 \%$ for four of the isolates (and by $90 \%$ for the fifth) when the inoculum droplets were amended with $100 \mu \mathrm{g} / \mathrm{ml}$ SHAM (Table 2). Similarly, appressorium formation was inhibited by 68 to $93 \%$ when unamended droplets were inoculated onto azoxystrobin-treated leaf disks, whereas no appressoria formed when SHAM was included in the inoculum. The SHAM amendment in the absence of fungicide had no significant $(P \leq 0.05)$ effect on conidium germination for four of the five isolates, although it did significantly re- duce appressorium formation for three of them (Table 2).

Because isolate Ott0030 demonstrated the highest percentage of appressorium formation in the presence of azoxystrobin and was most unequivocally responsive to the blockage of alternative respiration with SHAM (Table 2), it was chosen for the subsequent studies. When leaves were sprayed with commercially formulated azoxystrobin at a field rate of $200 \mathrm{mg} / \mathrm{liter}$, approximately $20 \%$ of the spores germinated and $8 \%$ formed appressoria. These frequencies increased to 47 and $14 \%$, respectively, when the azoxystrobin concentration was reduced to $20 \mathrm{mg} / \mathrm{liter}$ (Table 3 ), and were similar to the frequencies observed when leaves were soaked in the same concentration of technical grade azoxystrobin (Table 2). However, when conidia were incubated on the leaf in the presence of both SHAM and azoxystrobin, spore germination and appressorium formation were almost completely inhibited at both fungicide concentrations (Table 3). As before, neither the SHAM nor the $3 \%$ methanol/7\% acetone mixture had any effect on the germination or appressorium formation of isolate Ott0030 in the absence of the fungicide (Table 3 ).

In the presence of azoxystrobin at 200 $\mathrm{mg} /$ liter, G. bidwellii appeared capable of
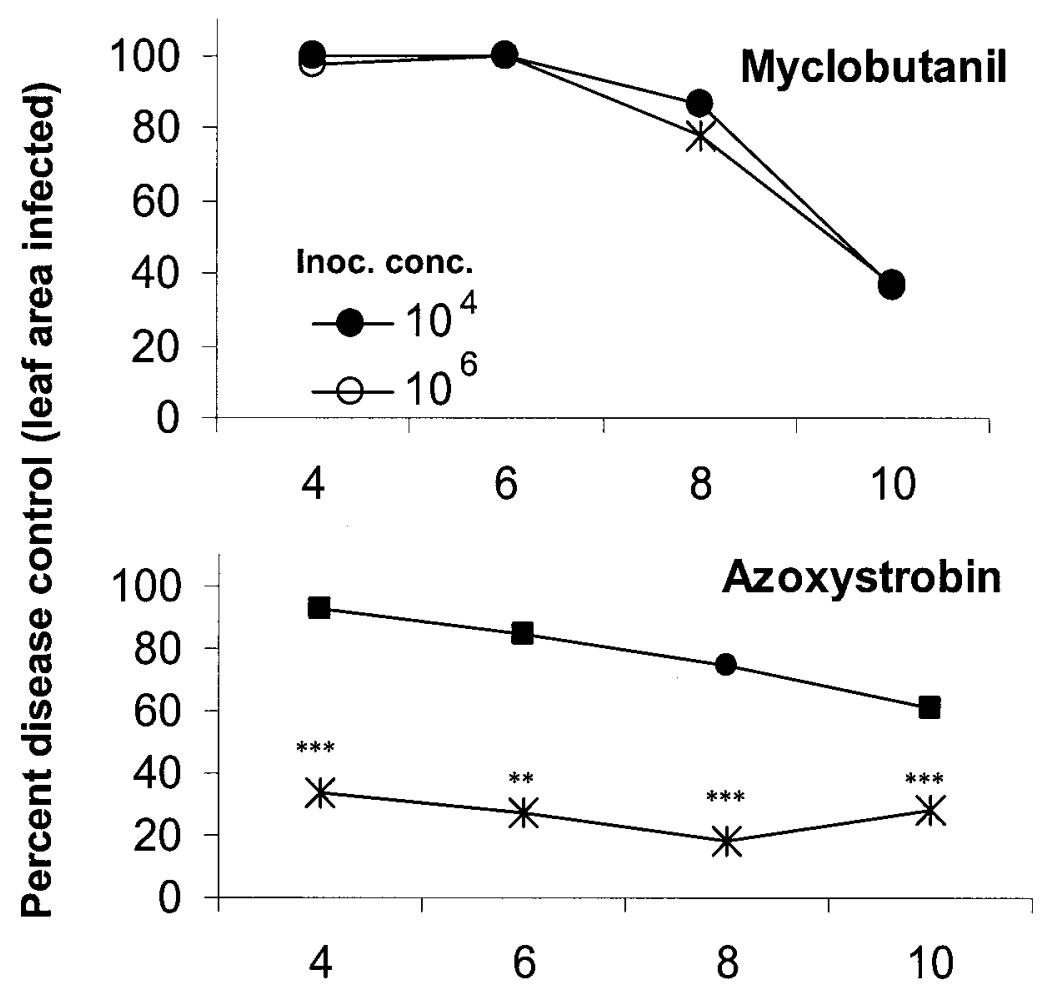

\section{Days postinoculation}

Fig. 3. Effect of inoculum dose on the postinfection activity of myclobutanil and azoxystrobin versus Guignardia bidwellii. Inoculated leaves were sprayed with myclobutanil (60 mg/liter), azoxystrobin $(128 \mathrm{mg} / \mathrm{liter})$, or water either $4,6,8$, or 10 days later. Data are presented as the percentage of control relative to the water check; values are means of two experiments with two leaves each rated on eight replicate seedlings per treatment. Significant differences between the two inoculum concentrations are indicated by $*(P \leq 0.1)$; ** $(P \leq 0.05)$; and $* * *(P \leq 0.01)$. 
establishing latent infections that were expressed when the leaves were killed with paraquat. For instance, 4 weeks after inoculation with $1 \times 10^{6}$ conidia per $\mathrm{ml}, 83 \%$ of the unsprayed leaves on intact plants showed typical black rot lesions (and $G$. bidwellii pycnidia were present in an identical frequency on unsprayed leaves treated with paraquat), whereas few symptoms were apparent on intact plants sprayed with azoxystrobin prior to inoculation. In contrast, G. bidwellii pycnidia had formed on
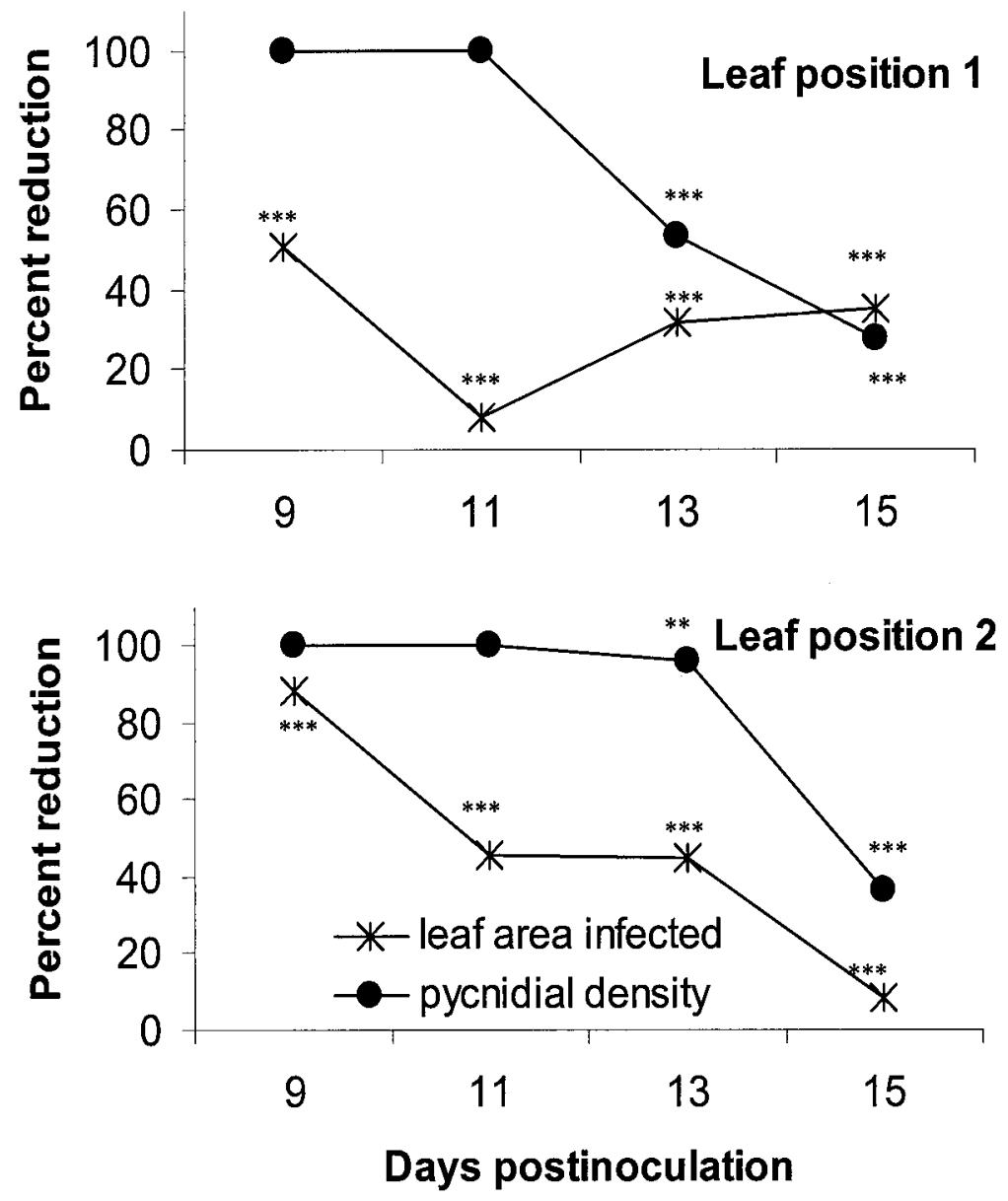

Fig. 4. Duration of the postinfection activity of myclobutanil. Eight replicate seedlings were inoculated with $2 \times 10^{5}$ conidia per $\mathrm{ml}$ and treated with myclobutanil $(60 \mathrm{mg} / \mathrm{liter})$ or water either 9,11 , 13 , or 15 days after inoculation. Data are presented as the percent reduction of the leaf area infected or the pycnidia per $\mathrm{mm}^{2}$ of necrotic leaf tissue, relative to the water check, averaged over two runs of the experiment. Significant differences from $100 \%$ reduction for each response are indicated by $*(P$ $\leq 0.1) ; *(P \leq 0.05)$; and $* * *(P \leq 0.01)$.

23 to $50 \%$ of the azoxystrobin-protected leaves that were treated with paraquat 1 to 7 days after inoculation (Table 4). When plants were inoculated with $2 \times 10^{5}$ conidia per $\mathrm{ml}$, no infections were evident on azoxystrobin-treated leaves that were not killed with paraquat, whereas $G$. bidwellii pycnidia formed on 7 to $20 \%$ of the protected leaves following paraquat treatment. The effect of the paraquat treatment was statistically significant $(P \leq 0.05)$, however, only when applied 3 days after inoculation (Table 4). No G. bidwellii pycnidia developed on the leaves of uninoculated seedlings treated with paraquat 3 days after the inoculation date.

When the experiments were reassessed 6 weeks after inoculation, the incidence of infection did not increase on leaves treated with paraquat. However, on intact plants protected with azoxystrobin, four new lesions appeared across the 10 seedlings inoculated with $2 \times 10^{5}$ conidia per $\mathrm{ml}$ in experiment 1 (increasing leaf infection incidence to $6 \%$ ), and 13 new lesions appeared on the plants in experiment 2 , increasing infection incidence to $16 \%$ (data not shown).

\section{DISCUSSION}

Myclobutanil provided complete control of lesion formation and pycnidium production when applied up to 6 days after inoculation or prior to lesion appearance (approximately 10 to 12 days after inoculation of grape seedlings under greenhouse conditions). In contrast, azoxystrobin provided significantly less curative activity than myclobutanil, although the extent of this control was surprising since Bartlett et al. (2) reported that only 1 to $3 \%$ of the azoxystrobin applied to a grape leaf was taken up within $24 \mathrm{~h}$. Although the exact mechanics of control were not determined in this study, it is possible that the disease control observed when azoxystrobin was applied 2 to 10 days after inoculation may have been due to diffusion of the compound from the cuticle to the subcuticular

Table 1. The effect of myclobutanil on formation of Guignardia bidwellii pycnidia when applied 9 to 15 days after inoculation

\begin{tabular}{|c|c|c|c|c|c|c|}
\hline $\begin{array}{l}\text { Days } \\
\text { postinoculation }^{\mathrm{a}}\end{array}$ & $\begin{array}{c}\text { Leaf } \\
\text { position }^{b}\end{array}$ & $\begin{array}{c}\text { No. lesions } \\
\text { before spray }\end{array}$ & $\begin{array}{l}\text { No. lesions w/pycnidia } \\
\text { before spray }^{\text {d }}\end{array}$ & $\begin{array}{c}\text { Additional lesions } \\
\text { w/pycnidia }\end{array}$ & $\begin{array}{l}\text { Final no. lesions w/ } \\
\text { pycnidia }^{f}(\% \text { control })\end{array}$ & $\begin{array}{c}\text { Final no. lesions } \\
\text { (\% control })\end{array}$ \\
\hline \multirow[t]{2}{*}{9} & 1 & 0 & 0 & 0 & $0(100)$ & $24(77)$ \\
\hline & 2 & 6 & 0 & 0 & $0(100)$ & $59(52)$ \\
\hline \multirow[t]{2}{*}{11} & 1 & 0 & 0 & 0 & $0(100)$ & $53(65)$ \\
\hline & 2 & 11 & 0 & 0 & $0(100)$ & $128(0)$ \\
\hline \multirow[t]{2}{*}{13} & 1 & 10 & 0 & 0 & $10(93)$ & $90(58)$ \\
\hline & 2 & 53 & 19 & 5 & $38(66)$ & $67(46)$ \\
\hline \multirow[t]{2}{*}{15} & 1 & 53 & 8 & 0 & $29(85)$ & $116(35)$ \\
\hline & 2 & 55 & 43 & 2 & $49(62)$ & $62(50)$ \\
\hline
\end{tabular}

\footnotetext{
a 'Riesling' seedlings were inoculated with $1 \times 10^{4}$ conidia per ml, then sprayed to runoff with commercially formulated myclobutanil at $60 \mathrm{mg} / \mathrm{liter}$ at the indicated times thereafter.

${ }^{\mathrm{b}}$ Leaf position no. 1 indicates the oldest still-expanding leaf at the time of inoculation, no. 2 indicates the leaf immediately above that.

$\mathrm{c}$ Total number of lesions apparent per indicated leaf on all eight replicate seedlings, immediately prior to the indicated myclobutanil application.

${ }^{\mathrm{d}}$ The number of lesions containing pycnidia on the indicated leaf immediately prior to the indicated myclobutanil treatment.

e The number of lesions that were not apparent before the indicated treatment, but which formed subsequently and contained pycnidia at harvest.

${ }^{\mathrm{f}}$ Total number of lesions containing pycnidia per indicated leaf (and percent reduction relative to the control) on all eight replicate seedlings 25 days after inoculation.

${ }^{\mathrm{g}}$ Total number of lesions present per indicated leaf (and percent reduction relative to the control) on all eight replicate seedlings 25 days after inoculation.
} 
space, where the pathogen resides until symptom expression (15). In contrast, azoxystrobin provided poor curative activity of Plasmopara viticola (27), which grows intercellularly and, therefore, farther away from where the compound accumulates. The control of pycnidium formation provided by curative sprays of azoxystrobin was erratic, but in pycnidia that did form, spore formation was reduced by 50 to $80 \%$, perhaps as a result of contact with the fungicide upon eruption of the pycnidia through the cuticle. The relative weakness of azoxystrobin's curative activity was further underscored by its pronounced reduction in postinfection activity at the higher inoculum concentration, whereas the postinfection activities of

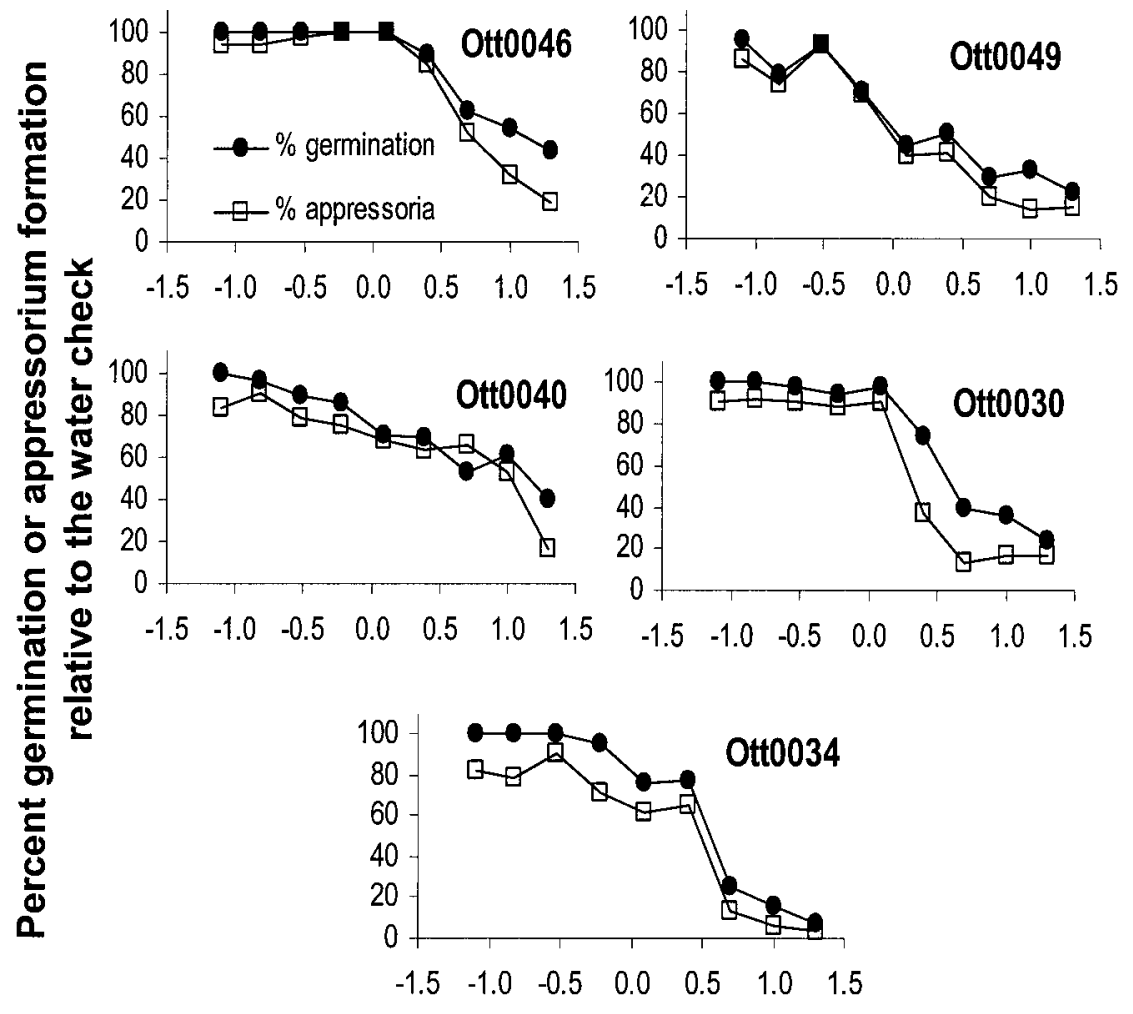

\section{Log of the fungicide concentration (mg/L)}

Fig. 5. Dose response curves for germination and appressorium formation by five isolates of Guignardia bidwellii with respect to azoxystrobin. Leaf disks from 'Riesling' seedlings were treated with azoxystrobin concentrations ranging from 0.08 to $20 \mathrm{mg} / \mathrm{liter}$, inoculated and assessed for germination and appressorium formation $24 \mathrm{~h}$ later. Values are means of two experiments in which each treatment contained six replicate leaf disks.

myclobutanil were unaffected over this inoculum range.

In the United States, myclobutanil currently is labeled for control of black rot up to $72 \mathrm{~h}$ after infection, but these results suggest it may have a longer period of curative activity, at least on foliage. If supported by subsequent field trials, such findings could increase its usefulness in curative spray programs $(5,8)$, where weather conditions, farm size, or other technical difficulties can limit the ability to react within $72 \mathrm{~h}$ of the start of an infection period. The antisporulant activity demonstrated by myclobutanil when applied anytime prior to symptom appearance may also reduce the availability of conidia from leaf lesions capable of infecting fruit in the field. For instance, during 5 years of studies in a vineyard of the Vitis interspecific hybrid 'Aurore', early-season sprays of myclobutanil provided no additional control of fruit rot, despite the preponderant release of primary inoculum prior to bloom, so long as the fungicide was applied immediately before bloom, plus 2 and 4 weeks later (10). However, it is likely that the immediate prebloom application suppressed the production of conidia from previous ascosporic infections on leaves, which may have increased the efficacy of the sprays applied to the young fruit. The extent of these postinfection activities is likely determined by the length of incubation period, which is in turn influenced by both temperature $(12,21)$ and tissue age $(12,15)$. Additional research also is needed to determine whether our results reported in this current study, which were obtained on seedling foliage under greenhouse conditions, apply equally to the control of fruit infections in the field. Furthermore, previous work demonstrated that postinfection applications of the DMI fungicide fenarimol to apple leaves inoculated with Venturia inaequalis are fungistatic rather than fungicidal $(3,9)$. The possibility

Table 2. The effect of salicylhydroxamic acid (SHAM) on conidial germination and appressorium formation of five isolates of Guignardia bidwellii on 'Riesling' leaf disks treated with azoxystrobin at $20 \mathrm{mg} / \mathrm{liter}$

\begin{tabular}{|c|c|c|c|c|c|c|}
\hline \multicolumn{2}{|c|}{ Treatment } & \multirow[b]{2}{*}{ Ott0046 } & \multirow[b]{2}{*}{ Ott0040 } & \multirow[b]{2}{*}{ Ott0030 } & \multirow[b]{2}{*}{ Ott0049 } & \multirow[b]{2}{*}{ Ott0034 } \\
\hline Leaf disk ${ }^{\mathrm{a}}$ & Inoculum $^{b}$ & & & & & \\
\hline \multicolumn{7}{|c|}{ Percent germination $^{c}$} \\
\hline Water & Water & $84.3 \mathrm{a}$ & $86.0 \mathrm{a}$ & $95.8 \mathrm{a}$ & $94.8 \mathrm{a}$ & $84.1 \mathrm{a}$ \\
\hline Azoxystrobin & Water & $48.4 \mathrm{c}$ & $35.1 \mathrm{~b}$ & $38.1 \mathrm{~b}$ & $27.4 \mathrm{~b}$ & $12.8 \mathrm{~b}$ \\
\hline Azoxystrobin & SHAM & $0.0 \mathrm{~d}$ & $8.2 \mathrm{c}$ & $0.4 \mathrm{c}$ & $0.7 \mathrm{c}$ & $0.3 \mathrm{c}$ \\
\hline Water & SHAM & $76.0 \mathrm{~b}$ & $65.3 \mathrm{a}$ & $96.8 \mathrm{a}$ & $97.0 \mathrm{a}$ & $72.9 \mathrm{a}$ \\
\hline Water & Methanol:acetone & $70.1 \mathrm{~b}$ & $82.4 \mathrm{a}$ & $96.7 \mathrm{a}$ & $95.8 \mathrm{a}$ & $80.8 \mathrm{a}$ \\
\hline \multicolumn{7}{|c|}{ Percent appressorium formation ${ }^{\mathrm{c}}$} \\
\hline Water & Water & $74.4 \mathrm{a}$ & $84.1 \mathrm{a}$ & $85.8 \mathrm{a}$ & $89.6 \mathrm{a}$ & $78.8 \mathrm{a}$ \\
\hline Azoxystrobin & Water & $14.2 \mathrm{~d}$ & $20.7 \mathrm{~b}$ & $27.4 \mathrm{c}$ & $19.2 \mathrm{c}$ & $5.2 \mathrm{c}$ \\
\hline Azoxystrobin & SHAM & $0.0 \mathrm{e}$ & $0.0 \mathrm{~d}$ & $0.0 \mathrm{~d}$ & $0.0 \mathrm{~d}$ & $0.0 \mathrm{~d}$ \\
\hline Water & SHAM & $23.5 \mathrm{c}$ & $6.2 \mathrm{c}$ & $84.0 \mathrm{a}$ & 89.8 a & $36.8 \mathrm{~b}$ \\
\hline Water & Methanol:acetone & $64.7 \mathrm{~b}$ & $83.5 \mathrm{a}$ & $69.7 \mathrm{~b}$ & $75.5 \mathrm{~b}$ & $76.4 \mathrm{a}$ \\
\hline
\end{tabular}

a 'Riesling' leaf disks were soaked in azoxystrobin at $20 \mathrm{mg} /$ liter or water for $1 \mathrm{~h}$ prior to inoculation.

${ }^{\mathrm{b}}$ Inoculum droplets were amended with $100 \mathrm{mg} / \mathrm{liter}$ SHAM dissolved in methanol plus acetone, with the methanol:acetone components only, or were left unamended (water). Inoculated disks were incubated for $24 \mathrm{~h}$ before staining and visual assessment.

${ }^{c}$ Values represent the means from 100 conidia examined on each of 12 replicate leaf disks per treatment. Treatment means were separated using the Waller-Duncan $k$-ratio $t$ test, $k=100$. 
that myclobutanil acts fungistatically against $G$. bidwellii rather than fungicidally, and its implication in disease management programs, should be investigated.

The range of $\mathrm{ED}_{50}$ values detected with respect to myclobutanil among 110 isolates of $G$. bidwellii was very narrow, with those for the most- and least-sensitive individuals being separated by a factor of only 16 . In contrast, minimum and maximum $\mathrm{ED}_{50}$ values among baseline isolates of Uncinula necator, a pathogen that has developed practical resistance to myclobutanil and other DMI fungicides, were found to be separated by a factor of 140 ; this spread from a DMI-resistant vineyard also were considered (28). Our study was not designed to monitor possible shifts in the distribution of myclobutanil sensitivities among G. bidwellii populations in a cross section of commercial vineyards. However, the narrow range of sensitivities that we encountered in both the unexposed population and that from a commercial vineyard with a history of regular DMI use and consistent black rot development suggests that the potential for such shifts may be less than for some other pathogens that have developed practical resistance to DMI extended to a factor of 740 when isolates

fungicides. Although G. bidwellii isolates with significantly reduced sensitivities to DMI fungicides have been developed in the laboratory (22), they have yet to be reported from the field. Whether this is because they are not problematic or have not been investigated adequately is uncertain. In either case, the baseline sensitivity distribution that we have developed for myclobutanil can be used in future efforts to monitor resistance to DMI fungicides among G. bidwellii populations. No distribution of baseline sensitivities to any DMI fungicide has been developed previously for this pathogen.

Whereas Olaya and Köller $(17,18)$ demonstrated that conidia of Venturia inaequalis could germinate via alternative respiration in the presence of kresoximmethyl on polystyrene, this appears to be the first report to demonstrate a similar phenomenon on plant tissues treated with a strobilurin. That is, at least some conidia from all five of the G. bidwellii isolates tested were capable of germinating and forming appressoria on leaves treated with azoxystrobin at $20 \mathrm{mg} / \mathrm{liter}$, as was the one isolate tested on leaves treated with the field rate of $200 \mathrm{mg} / \mathrm{liter}$. However, these capabilities were almost completely ne-

Table 3. Effect of salicylhydroxamic acid (SHAM) on conidium germination and appressorium formation for Guignardia bidwellii isolate Ott0030 on 'Riesling' leaf disks treated with commercially formulated azoxystrobin

\begin{tabular}{llcc}
\hline \multicolumn{2}{c}{ Treatment } & & corssorium \\
\cline { 1 - 2 } Leaf disk $^{\mathbf{a}}$ & Inoculum $^{\mathbf{b}}$ & Germination (\%) $^{\mathbf{c}}$ & $\begin{array}{c}\text { Appressorion } \\
\text { formation }\end{array}$ \\
\hline Water & Water & $95.8 \mathrm{a}$ & $89.5 \mathrm{a}$ \\
Azoxystrobin (200 mg/liter) & Water & $20.4 \mathrm{c}$ & $7.8 \mathrm{~b}$ \\
Azoxystrobin (200 mg/liter) & SHAM & $2.4 \mathrm{~d}$ & $0.4 \mathrm{c}$ \\
Azoxystrobin (20 mg/liter) & Water & $46.9 \mathrm{~b}$ & $14.3 \mathrm{~b}$ \\
Azoxystrobin (20 mg/liter) & SHAM & $0.7 \mathrm{~d}$ & $0.2 \mathrm{c}$ \\
Water & SHAM & $94.0 \mathrm{a}$ & $83.4 \mathrm{a}$ \\
Water & Methanol:acetone & $98.8 \mathrm{a}$ & $92.3 \mathrm{a}$ \\
\hline
\end{tabular}

a 'Riesling' leaf disks were soaked in azoxystrobin at 200 or $20 \mathrm{mg} /$ liter or water for $1 \mathrm{~h}$ prior to inoculation with conidia of isolate Ott0030.

${ }^{\mathrm{b}}$ Inoculum droplets were amended with $100 \mathrm{mg} /$ liter SHAM dissolved in methanol plus acetone, with the methanol:acetone components only, or were left unamended (water). Inoculated disks were incubated for $24 \mathrm{~h}$ before staining and visual assessment.

${ }^{c}$ Values represent the means from 100 conidia examined on each of 12 replicate leaf disks per treatment. Treatment means were separated using the Waller-Duncan $k$-ratio $t$ test, $k=100$.

Table 4. Latent survival of Guignardia bidwellii in leaves of 'Riesling' seedlings treated with commercially formulated azoxystrobin at $200 \mathrm{mg} / \mathrm{liter}$

\begin{tabular}{|c|c|c|c|}
\hline \multirow[b]{2}{*}{ Fungicide $^{\mathbf{a}}$} & \multirow[b]{2}{*}{ Paraquat (days) ${ }^{b}$} & \multicolumn{2}{|c|}{ Infection incidence ${ }^{c}$} \\
\hline & & Experiment 1 & Experiment 2 \\
\hline \multirow[t]{2}{*}{ None } & None & $93 \mathrm{a}$ & $83 \mathrm{a}$ \\
\hline & 3 & $83 \mathrm{a}$ & $83 \mathrm{a}$ \\
\hline \multirow[t]{4}{*}{ Azoxystrobin } & None & $0 \mathrm{c}$ & $7 \mathrm{~d}$ \\
\hline & 1 & $7 \mathrm{c}$ & $27 \mathrm{c}$ \\
\hline & 3 & $20 \mathrm{~b}$ & $23 \mathrm{c}$ \\
\hline & 7 & $7 \mathrm{c}$ & $50 \mathrm{~b}$ \\
\hline
\end{tabular}

${ }^{a}$ Seedlings with four to five fully expanded leaves were sprayed with water or azoxystrobin at 200 $\mathrm{mg} / \mathrm{liter}$ (Abound 80WG) $24 \mathrm{~h}$ prior to inoculation with G. bidwellii conidia.

${ }^{\mathrm{b}}$ Selected seedlings were sprayed with $0.1 \%$ paraquat either 1,3 , or 7 days after inoculation.

${ }^{\mathrm{c}}$ Infection incidence was determined by observing leaves for the presence or absence of G. bidwellii pycnidia 4 weeks after inoculation. Reported values are the means for 10 replicate seedlings per treatment. Seedlings in experiments 1 and 2 were inoculated with $2 \times 10^{5}$ and $1 \times 10^{6}$ conidia per $\mathrm{ml}$, respectively. Treatment means within a column only were separated using the Waller-Duncan $k$ ratio $t$ test, $k=100$. gated by the addition of SHAM, indicating that the processes occurring in its absence were the consequence of alternative respiration. Such respiration is induced by fungicide-dependent blockage of the $\mathrm{bc}_{1}$ complex $(4,16)$, which generates $\mathrm{O}_{2}$ and subsequently induces the alternative oxidase gene in affected mitochondria (16). Our work, along with the work of AvilaAdame and Köller (1), does not support the hypothesis put forward by Mizutani et al. (16) that plant-produced flavonoids scavenge $\mathrm{O}_{2}^{-}$and thereby prevent induction of the alternative oxidase gene in planta, leading to excellent disease control by the strobilurins. Our studies with azoxystrobintreated plants that were inoculated with $G$. bidwellii and subsequently killed with paraquat complement our leaf disk tests to suggest that alternative respiration is not completely inhibited by plant-produced flavonoids. That is, whereas little or no disease was evident on azoxystrobinprotected live plants 4 to 6 weeks after inoculation, latent infections apparently were established on a significant proportion of their leaves, becoming active once the tissue had been killed. Similarly, AvilaAdame and Köller (1) demonstrated that although the effectiveness of the alternative respiration rescue executed by Magnaporthe grisea was reduced on azoxystrobin-treated barley leaves as compared to complete media, symptom expression did occur. Further research is needed to determine the precise mechanism(s) of this phenomenon and its potential effect on disease control and pathogen selection under various fungicide-use regimes in the field.

When developing integrated management programs, an in-depth understanding of the physical modes of action of the available fungicides fosters an informed use of these compounds. Although our research demonstrates the superior curative activity of myclobutanil over azoxystrobin for black rot management, it did not address the relative protective activities of the two compounds. Azoxystrobin clearly provides better control of grapevine downy mildew when used in a protective rather than a curative mode (27). The prolonged curative activity of myclobutanil (and, perhaps, the similarly effective triazole fungicide, tebuconazole) provides flexibility in the timing of applications for black rot control that is not provided by azoxystrobin. Such may account, in part, for the modest but consistent improvements in black rot control provided by these DMI fungicides over the strobilurins in field trials in New York (23-25).

However, the integrated management of multiple diseases often requires compromises. For example, azoxystrobin currently is used by many New York growers in the immediate prebloom and early postbloom periods critical for control of powdery mildew, downy mildew, and black rot because it 
is effective against DMI-resistant isolates of Uncinula necator (28), it is highly effective against downy mildew (26), and it provides good control of black rot under commercial conditions (personal observation). It is uncertain to what extent the use of azoxystrobin or other strobilurin fungicides rather than myclobutanil may affect black rot control when the first spray is delayed until immediately prior to bloom and extensive curative activity is not available.

\section{ACKNOWLEDGMENTS}

We thank W. Köller, F. P. Wong, H. C. Hoch, and B. D. Shaw for technical advice and D. M. Gadoury, R. C. Seem, W. E. Fry, and B. Reisch for critically reviewing the manuscript. Funding was provided in part by the Lake Erie Regional Grape Program, the New York Wine and Grape Foundation, and the Viticulture Consortium-East.

\section{LITERATURE CITED}

1. Avila-Adame, C., and Köller, W. 2002. Disruption of the alternative oxidase gene in Magnaporthe grisea and its impact on host infection. Mol. Plant-Microbe Interact. 15:493-500.

2. Bartlett, D. W., Clough, J. M., Godwin, J. R., Hall, A. A., Hamer, M., and Parr-Dobrzanski, B. 2002. The strobilurin fungicides. Pest Manag. Sci. 58:649-662.

3. Berton, O., Gadoury, D. M., Seem, R. C., and Wilcox, W. F. 1999. Ontogenic resistance to apple scab, post-infection use of fenarimol, and the distribution of symptom expression. Phytopathology 89:S6.

4. Brandt, U., Schaegger, H., and Von Jagow, G. 1988. Characterization of binding of the methoxyacrylate inhibitors to mitochondrial cytochrome c reductase. Eur. J. Biochem. 173:499-506.

5. Ellis, M. A., Madden, L. V., and Wilson, L. L. 1986. Electronic grape black rot predictor for scheduling fungicides with curative activity. Plant Dis. 70:938-940.

6. Erickson, E. O., and Wilcox, W. F. 1997. Distributions of sensitivities to three sterol demethylation inhibitor fungicides among populations of Uncinula necator sensitive and resistant to triadimefon. Phytopathology 87:784-791.

7. Ferrin, D. M., and Ramsdell, D. C. 1977. Ascospore dispersal and infection of grapes by Guignardia bidwellii, the causal agent of grape black rot disease. Phytopathology 67:1501-1505.

8. Gadoury, D. M., Pearson, R. C., Seem, R. C., and Park, E. W. 1997. Integrating the control programs for fungal diseases of grapevine in the Northeastern United States. Vitic. Enol. Sci. 52:140-147.

9. Hoch, H. C., and Skolznik, M. 1979. Viability of Venturia inaequalis in chlorotic flecks resulting from fungicide applications to infected Malus leaves. Phytopathology 69:456-462.

10. Hoffman, L. E., and Wilcox, W. F. 2002. Utilizing epidemiological investigations to optimize management of grape black rot. Phytopathology 92:676-680.

11. Hoffman, L. E., Wilcox, W. F., Gadoury, D. M., and Seem, R. C. 2000. Postinfection activities of myclobutanil and azoxystrobin against Guignardia bidwellii. Phytopathology 90:S35.

12. Hoffman, L. E., Wilcox, W. F., Gadoury, D. M., and Seem, R. C. 2002. The influence of grape berry age on susceptibility to Guignardia bidwellii and its incubation period length. Phytopathology 92:1068-1076.

13. Köller, W. 1994. Chemical control of apple scab - status quo and future. Norw. J. Agric. Sci. Suppl. 0:149-170.

14. Kuo, K., and Hoch, H. C. 1996. Germination of Phyllosticta ampelicida pycnidiospores: Prerequisite of adhesion to the substratum and the relationship of substratum wettability. Fung. Genet. Biol. 20:18-29.

15. Kuo, K., and Hoch, H. C. 1996. The parasitic relationship between Phyllosticta ampelicida and Vitis vinifera. Mycologia 88:626-634.

16. Mizutani, A., Miki, N., Yukioka, H., Tamura, H., and Masuko, M. 1996. A possible mechanism of control of rice blast disease by a novel alkoxyiminoacetamide fungicide, SSF126. Phytopathology 86:295-300.

17. Olaya, G., and Köller, W. 1999. Baseline sensitivities of Venturia inaequalis populations to the strobilurin fungicide kresoximmethyl. Plant Dis. 83:274-278.

18. Olaya, G., and Köller, W. 1999. Diversity of kresoxim-methyl sensitivities in baseline populations of Venturia inaequalis. Pestic. Sci. 55:1083-1088.

19. Ramsdell, D. C., and Milholland, R. D. 1988. Black Rot. Pages 15-17 in: Compendium of Grape Diseases. R. C. Pearson and A. C. Goheen, eds. American Phytopathological Society, St. Paul, MN.

20. Skolznik, M. 1981. Physical modes of action of sterol-inhibiting fungicides against apple diseases. Plant Dis. 65:981-985.

21. Spotts, R. A. 1980. Infection of grape by Guignardia bidwellii - factors affecting lesion development, conidia dispersal, and conidial populations on leaves. Phytopathology 70:252-255.

22. Thind, T. S., Clerjeau, M., and Olivier, J. M. 1986. First observations on resistance in Ven turia inaequalis and Guignardia bidwellii to ergosterol-biosynthesis inhibitors in France. Proc. 1986 Br. Crop Prot. Conf.: 491-498.

23. Wilcox, W. F., and Riegel, D. G. 1996. Evaluation of fungicides and spray timings for control of black rot and downy mildew of grapes, 1995. Fungic. Nematicide Tests 51:74-75.

24. Wilcox, W. F., and Riegel, D. G. 1997. Evaluation of fungicide programs for control of black rot of grapes, 1996. Fungic. Nematicide Tests 52:87.

25. Wilcox, W. F., Riegel, D. G., and Emele, L. R. 1999. Evaluation of fungicide programs for control of grape black rot, 1998. Fungic. Nematicide Tests 54:110

26. Wilcox, W. F., Riegel, D. G., and Wong, F. P. 1999. Evaluation of fungicide programs for control of downy mildew of grapes, 1998. Fungic. Nematicide Tests 54:111.

27. Wong, F. P., and Wilcox, W. F. 2001. Comparative physical modes of action of azoxystrobin, mancozeb, and metalaxyl against Plasmopara viticola (grapevine downy mildew). Plant Dis. 85:649-656.

28. Wong, F. P., and Wilcox, W. F. 2002. Sensitivity to azoxystrobin among isolates of $U n$ cinula necator: Baseline distribution and relationship to myclobutanil sensitivity. Plant Dis. 86:394-404.

29. Ypema, H. L., and Gold, R. E. 1999. Kresoxim-methyl: Modification of a naturally occurring compound to produce a new fungicide. Plant Dis. 83:4-19.

30. Ypema, H. L., and Gubler, W. D. 1997. Longterm effect of temperature and triadimefon on proliferation of Uncinula necator: Implications for fungicide resistance and disease risk assessment. Plant Dis. 81:1187-1192.

31. Ypema, H. L., Ypema, M., and Gubler, W. D. 1997. Sensitivity of Uncinula necator to benomyl, triadimefon, myclobutanil, and fenarimol in California. Plant Dis. 81:293-297.

32. Ziogas, B. N., Baldwin, B. C., and Young, J. E. 1997. Alternative respiration: A biochemical mechanism of resistance to azoxystrobin (ICIA 5504) in Septoria tritici. Pestic. Sci. 50:28-34 